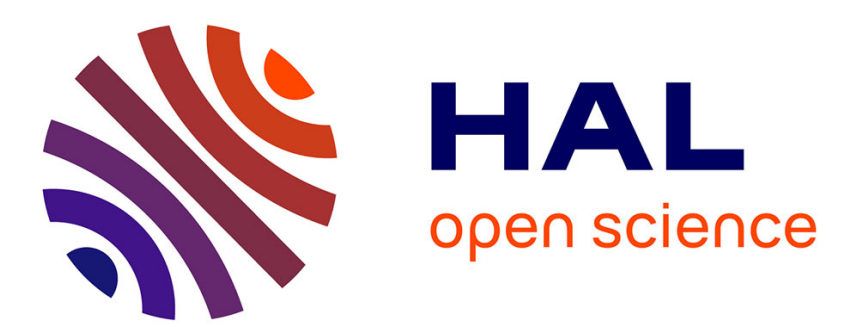

\title{
Examining potential mechanisms underlying the Wikipedia gender gap through a collaborative editing task
}

Christina Shane-Simpson, Kristen Gillespie-Lynch

\section{- To cite this version:}

Christina Shane-Simpson, Kristen Gillespie-Lynch. Examining potential mechanisms underlying the Wikipedia gender gap through a collaborative editing task. Computers in Human Behavior, 2017, 66, pp.312-328. 10.1016/j.chb.2016.09.043 . hal-01612306

\section{HAL Id: hal-01612306 https://hal.science/hal-01612306}

Submitted on 6 Oct 2017

HAL is a multi-disciplinary open access archive for the deposit and dissemination of scientific research documents, whether they are published or not. The documents may come from teaching and research institutions in France or abroad, or from public or private research centers.
L'archive ouverte pluridisciplinaire HAL, est destinée au dépôt et à la diffusion de documents scientifiques de niveau recherche, publiés ou non, émanant des établissements d'enseignement et de recherche français ou étrangers, des laboratoires publics ou privés. 
Examining Potential Mechanisms Underlying the Wikipedia Gender Gap through a Collaborative Editing Task

\author{
Christina Shane-Simpson ${ }^{12}$ \\ Christinam.shane@gmail.com \\ Kristen Gillespie-Lynch ${ }^{12}$ \\ Kgillyn@gmail.com \\ ${ }^{1}$ The Graduate Center, CUNY \\ 365 Fifth Avenue New York, NY 10016 \\ ${ }^{2}$ The College of Staten Island \\ 2800 Victory Blvd, Staten Island, NY 10314
}

Corresponding Author:

Christina Shane-Simpson at Christinam.shane@ gmail.com

Psychology Department

The Graduate Center, CUNY

365 Fifth Avenue, New York, NY 10016 


\section{Highlights}

- Examined mechanisms underlying Wikipedia gender gap using a collaborative editing task.

- Women edited more overall; men trended towards editing more in a Wikipedialike condition.

- An anonymous peer editor was more often viewed as male.

- Women viewed the anonymous editor as more critical than a gender-neutral peer.

- Visible female Wikipedians and constructive feedback may alleviate the gender gap. 


\begin{abstract}
Research has identified a significant gender gap on the online encyclopedia, Wikipedia. The current research used a mixed experimental (type of feedback) and quasiexperimental (gender) design to examine the editing behaviors of college students during a public, collaborative editing task to identify potential factors underlying the Wikipedia gender gap. Overall, women edited more than men. However, in the editing condition most akin to Wikipedia, wherein female peer editors were underrepresented in the essay edits and feedback from peers was neutral, men trended towards adding more content than woman. Women added more content than men in this male-dominated essay condition when peer editors modeled constructive feedback. Although the type of edits from peer editors was counterbalanced, participants typically viewed an anonymous peer editor as male. Women viewed the anonymous editor as more critical of the participant's own work when compared with a gender-neutral peer editor. These results suggest that visible female editors on Wikipedia and broader encouragement of the use of constructive feedback may begin to alleviate the Wikipedia gender gap. Furthermore, the relatively high proportion of anonymous editors may exacerbate the Wikipedia gender gap, as anonymity may often be perceived as male and more critical.
\end{abstract}

Keywords: Online, gender, editing, communication, Wikipedia 
Examining Potential Mechanisms Underlying the Wikipedia Gender Gap through a Collaborative Editing Task

\subsection{Introduction}

Recent research has revealed a Wikipedia gender gap; women edit Wikipedia at significantly lower volumes than men (Collier \& Bear, 2012; Eckert \& Steiner, 2013; Glott, Schmidt, \& Ghosh, 2010; Hill \& Shaw, 2013; Lam et al., 2011; Pande, 2011). Explanations for this gender gap often highlight the contentious nature of Wikipedia as favoring traditionally male communicative styles (Collier \& Bear, 2012; Lam et al., 2011; Laniado et al., 2012), as women may be less sure of their expertise, more often targeted for harassment, and more negatively affected by critical feedback than men (Bear \& Collier, 2016). Consequently, women may contribute more during online discussions rather than through visible, article-based Wikipedia editing (Lam et al., 2011). Gender differences in Internet familiarity (Hargittai \& Shaw, 2015), the desire to contribute to the common good, and differences in leisure time may also contribute to the gender gap.

The Wikipedia mission statement centers on the empowerment and engagement of people around the world to collect and disseminate knowledge (see Wikimedia Foundation Mission Statement, 2015; Wales, 2016). Despite Wikipedia's commitment to involving diverse people in the dissemination of shared knowledge, gender inequality in Wikipedia editing has been well documented through survey research (e.g., Collier \& Bear, 2012). Consequently, the barriers that women encounter obtaining equality in other environments (e.g., Fenstermaker \& West, 2002) also persist on Wikipedia. 
Injustice towards women online has also been documented on other sites. For example, in a review of the comments left on The Guardian website, researchers found that their female opinion writers (compared with those that were male) experienced the greatest levels of harassment through comments left on article posts (Gardiner et al., 2016). These trolling behaviors may represent a unique form of discrimination found online; due to the nature of many online environments, harassing behaviors can be hidden under a veil of anonymity for the antagonist. Trolling may be particularly salient on sites like Wikipedia that do not require users to identify personal information in a profile. In fact, gender inequality appears to be particularly apparent on anonymous sites such as gaming sites (see Thacker \& Griffiths, 2012) and discussion forums (Herring, Job-Sluder, Scheckler, \& Barab, 2002). Consequently, these widespread online inequalities may impact how women participate in certain collaborative environments and may underlie the current Wikipedia gender gap.

While a wealth of interventions have been proposed to address the Wikipedia gender gap (see https://meta.wikimedia.org/wiki/Grants:IdeaLab/Inspire), the majority of the prior research focuses on self-reported survey data or content analyses of Wikipedia editing and thus lacks a systematic examination of how gender disparities in collaborative editing arise. This lack of research examining potential mechanisms underlying gender inequality on Wikipedia may prevent the gap from closing, as interventions designed to address the gap may miss these underlying mechanisms. These issues have led to surfacelevel interventions that only target specified groups of women and neglect to include the majority of potential female editors of varying ages, ethnicities, and professional affiliations. For example, Wikipedia edit-a-thons, which target women or Wikipedia 
articles on women, have been implemented in major cities. While beneficial in improving the content of Wikipedia articles, these edit-a-thons are often dominated by current female Wikipedians. Systematic analyses of the mechanisms underlying the Wikipedia gender gap could be used to broaden the focus of interventions to include a wider range of female Wikipedians. Such research has the potential to remove barriers that women encounter when attempting to edit, bringing Wikipedia closer to its goal of empowering diverse people to share in the work of collecting, refining, and disseminating knowledge.

\subsection{Inequalities on Wikipedia}

Research has found inequalities in the overall volume of editing, revealing that less than $10 \%$ of Wikipedians contribute over $90 \%$ of the total number of contributions on the English Wikipedia (Ortega, Gonzalez-Barahona, \& Robles, 2008). In addition to this more general inequality, the identification of a gender disparity, in which men edit at greater volumes on the English Wikipedia, was revealed in recent Wikipedia surveys (Glott, Schmidt, \& Ghosh, 2010; Hill \& Shaw, 2013; Pande, 2011), analyses of Wikipedia itself (Lam et al., 2011), and subsequent research about the media's often belittling responses to reports about the Wikipedia gender gap (Eckert \& Steiner, 2013). Only $22.7 \%$ of U.S. Wikipedians on the English Wikipedia self-identify as female relative to those who identify as male (Hill \& Shaw, 2013), a number that increased only slightly (after more precise data analysis) from the original estimate of $17.8 \%$ female Wikipedians in the Wikimedia Foundation Survey (see Glott, Ghosh, \& Schmidt, 2010).

Recent research also highlights the persistence and prevalence of the Wikipedia gender gap beyond the English Wikipedia. A 2016 study conducted by Mass and Zelenkauskaite found that in comparison with self-identified male users, women 
represented a smaller percentage of Wikipedians in almost all of the current Wikipedia online encyclopedias (across cultures). Some of the Wikipedia environments with the smallest proportion of female users were Hindi, Bengali, Persian, and Chinese. Even in consideration of these findings, it remains unknown how gender is communicated in this public, collaborative space, which might influence how men and women actively engage on Wikipedia.

\subsection{Underlying Motivations for Wikipedia Editing}

Researchers also attribute online participation in the Wikipedia community to personal motivation, cultural and linguistic factors, and antecedents of participation (Okoli, Mehdi, Mesgari, Nielsen, \& Lanamaki, 2012). In regards to personal motivation, research has revealed that Wikipedians express a strong desire to give back in an effort to enhance public knowledge of complex phenomenon, heightened intrinsic motivation, and heightened altruistic behaviors and motivations (Baytiyeh \& Pfaffman, 2010; Cho, Chen, \& Chung, 2010; for a review see Jullien, 2012; Kuznetsov, 2006; Nov, 2007; Okoli et al., 2012; Shroer \& Hertel, 2009).

Potential gender differences in many of these characteristics have not yet been identified on Wikipedia, which is likely due to the use of unstandardized measures or lack of exploration and/or reporting of gender in data analyses (see Okoli et al., 2012). Prior studies indicate that women are more altruistic than men, specifically when the cost of the behavior is expensive (Andreaoni \& Vesterlund, 2001). This finding implies that women would be more active on Wikipedia. However, the current gender gap contrasts with this finding, suggesting that even if women have a strong desire to contribute on Wikipedia, they may experience significant barriers when attempting to do so. 
Studies also suggest that the gender gap may be fueled by gender differences in Internet familiarity and Internet use, specifically for highly skilled editors, who are more likely to be male (Hargittai \& Shaw, 2015). In younger age groups, studies find that boys report (via surveys) more confidence in their computer-based skills when compared with girls, are more attracted to computer-based environments, and express more dominance in these spaces (Comber, Cholley, Hargreaves, \& Dorn, 1997; Underwood, Underwood, $\&$ Wood, 2000). Survey research conducted by Bear and Collier $(2016)(N=1,598)$ on Wikipedia found that women also reported less confidence in their editing expertise and greater discomfort with editing when compared with men. In addition, women reported a greater internal, negative response to critical feedback from other Wikipedians than men. Both lack of confidence in expertise and discomfort with editing were significant predictors of the number of articles edited by participants.

As novice editors begin editing on Wikipedia, they may receive positive or negative feedback from other, unknown editors. The nature and reception of this feedback might guide whether/how these novice editors make future edits on the site. Research has used edit revert-detection methods on Wikipedia data from the Main Namespace area, an area that includes a set of Wikipedia pages whose names begin with a specific word. For example, this might include all article pages on Wikipedia that begin with Main/Article. Lam and colleagues (2011) explored whether an editor's contributions on Wikipedia were their first edits or if they had edited more than once to identify whether female or male editors were more likely to have early edits reverted. Results revealed that women were more likely to have their edits reverted on Wikipedia. Given that novice women were just as likely as novice men to leave Wikipedia after an edit 
reversion, their greater number of reverted edits might also result in fewer women continuing their editing on Wikipedia articles.

\subsubsection{Explaining the gap: Contentious nature of Wikipedia}

Social dynamics, such as forced interactions with those who use dissimilar communicative patterns may also prevent certain groups of individuals from Wikipedia editing. When women begin editing on public sites, such as Wikipedia, they encounter a largely male-biased editing community. In examining Wikipedia discussions, researchers found evidence of emotional homophily, where Wikipedians with specific communicative styles tend to engage with similar (versus dissimilar) others (Laniado, Kaltenbrunner, Castillo, \& Morell, 2012). Laniado and colleagues (2012) found that Wikipedians sent and received more messages from users who communicated in a similar style, such as matching the valence of the communication (e.g., happiness, satisfaction, dissatisfaction, despair). Consequently, women may refrain from larger contributions to public editing sites that are dominated by male users as a result of forced interactions with those who communicate in ways that are dissimilar from them. These barriers may also parallel those experienced by other "out-groups" (i.e., minority groups) who have a strong desire to contribute on Wikipedia, but feel too disconnected from the current community of online participants.

Survey research conducted with 40,699 English Wikipedians also found that women might avoid contentious or controversial discussions on Wikipedia (Collier \& Bear, 2012). Women were more likely to report that a conflict with another Wikipedian resulted in the halting of their participation on Wikipedia (Collier \& Bear, 2012). In addition, women were $31 \%$ more likely than men to identify that a fear of being criticized 
was a significant reason for not wanting to be more active on Wikipedia. This selfreported avoidance of conflict and criticism may result in differences in editing behaviors by female Wikipedians when compared with their male counterparts.

In another study using a content analysis of English Wikipedia talk pages, researchers measured the emotional valence and content of Wikipedia discussions using the Affective Norms of English Words assessment; this measure allowed researchers to assess the valence, level of arousal, and level of dominance found in conversations (Laniado et al., 2012). Results indicated that women were more oriented towards discussions with a positive tone and received more positive comments on their user talk pages. The majority of the prior research, most of which relies on content analyses of Wikipedia articles and talk pages (Lam et al., 2011; Landiado et al., 2012) or self-report surveys (Collier \& Bear, 2012), suggests that women on Wikipedia may favor a socially harmonious style of communication parallel to female preferences found in offline environments (Leaper \& Smith, 2004; Tannen, 1991).

Nevertheless, another study uncovered evidence that Wikipedia articles with a greater concentration of female editors were also more controversial (or argumentative) in nature and that women were more likely to be indefinitely blocked on Wikipedia due to vandalism or other infractions (Lam et al., 2011). In their study, Lam and colleagues (2011) noted participants' self-reported gender (via their user pages) and explored the edit protection status of articles that had a high concentration of male or female editors. Heavily protected articles often contain disputes, vandalism, or controversies, all of which are more likely to display contentious communicative patterns. These protected articles are also restricted from further editing by new or anonymous editors, as these two 
types of editors are commonly the culprits of the vandalism/spam on the article (Lam et al., 2011). Results indicated that in comparison with the male-dominated pages, more of the female-dominated pages were flagged as protected on Wikipedia (5.2\% of the female articles, $2.4 \%$ of the male articles). However, the researchers did not examine whether these particular articles held more disputes than other, non-protected articles; it is possible that these particular articles simply contained more acts of vandalism.

These results suggest that the highly concentrated, female-edited articles may actually contain more controversies and tensions than the male-dominated articles. As a result of this conflicting research, additional studies are needed to more clearly evaluate if women are favoring more socially harmonious behaviors in online environments.

\subsubsection{Explaining the gap: More discussion and less content editing}

A study by Lam and colleagues (2011) found that women tend to contribute more often via User and User Talk Pages. The main function of these pages centers on discussion with others, or socially oriented behaviors more often attributed to feminine communicative styles. As women are contributing on user talk pages, they also edit to a lesser extent on main articles and article talk pages, which focus on discussions of article content (Lam et al., 2011). This trade-off may result in women contributing to the content of Wikipedia articles to a lesser extent, and contributing to a greater extent in discussions with other Wikipedians.

\subsubsection{Explaining the gap: Inequality in leisure activity}

As another potential explanation for the gap, the gender inequality in leisure activity and time allocated for such activity has persisted over the years (see Bittman \& Wajcman, 2000 for a review). Over time, as women have taken on the roles of working- 
parent and unpaid (or second shift) family caregiver, time constraints have tightened on their amount and quality of their leisure time (Bittman \& Wajcman, 2000). With decreasing opportunities for recreational activities, women may also find fewer opportunities for unpaid, online collaborative endeavors, such as those found on Wikipedia-like environments. Restraints on time and resources may prevent women from actively contributing on Wikipedia, particularly on a regular basis, even if they have a heightened interest in contributing to the public dissemination of knowledge.

\subsubsection{Explaining the gap: Harassment targeting women}

Women's desire to contribute on Wikipedia may also be hindered by the prevalence of harassment directed towards women in online environments (see Gardiner et al., 2016; Herring, 2000). Women may feel unwelcome on certain Wikipedia spaces, such as article pages, and may refrain from contributions due to their perceptions of or actual interactions with other Wikipedians. Many of these unwelcoming practices have not been studied in the Wikipedia literature, even though online harassment directed towards women has been studied on other collaborative sites such as gaming environments and discussion forums (Gardiner et al., 2016; Herring, 2000; Herring, JobSluder, Scheckler, \& Barab, 2002; Thacker \& Griffiths, 2012).

\subsubsection{Explaining the gap: Perceptions of and Interactions with Other Editors}

Stereotypes associated with gender identity may also contribute to gender differences in online collaboration. Ghavami and Peplau (2012) identified unique attributes associated with varying identities, such as the perpetuated stereotype that Asian American women are intelligent, quiet, and short. As an enactment of her offline identity, these Asian American female stereotypes likely influence how an Asian American 
woman behaves online. In turn, the community's reception of that identity is influenced by pre-conceived stereotypes and, consequently, Asian American women may experience online power dynamics that parallel those from offline environments. In consideration of these online power dynamics, one's gender identity and the gender of other editors may influence how a person engages in collaborative editing. As such, motivations for online collaborative editing may be driven by both individual-level and environmental factors (such as the gender composition of editing environments).

Indeed, prior research suggests that offline communicative patterns may replicate in online environments. For example, male-dominated chatrooms are often more aggressive, with frequent displays of dominance during communication, while femaledominated rooms contain more relationship-based communicative strategies such as reaching out to new people and expressing emotions (Soukup, 1999).

The gender composition of editing environments has been studied most extensively in educational online collaborative spaces (see Prinsen, Volman, \& Terwel, 2007 for a review). Findings from this literature may clarify possible reasons behind the current Wikipedia gender gap. In a study with college students, researchers found that male-only groups used more aggressive language, changed their opinions the least, and were least satisfied with the group work when compared with female-only and mixedgender groups (Savicki, Kelley, and Lingenfelter, 1996a). Female-only groups were most likely to use individually oriented language, change their opinions, and were most satisfied with their group work. These results also suggest that mixed-gender groups may produce the most communication, and that male-only groups may perpetuate and even heighten offline male stereotypes of dominance or aggression. In fact, another study by 
Savicki, Kelley, \& Lingenfelter (1996b) found that male-only groups also contained more tension (e.g., attacking an opposing opinion) and abusive language in their messaging when compared with mixed-gender and then female-only groups.

In mixed gender groups, researchers have found that the amount of participation and kinds of participation varies by gender (Selfe \& Meyer, 1991). In a study using asynchronous online conferencing, participants sent messages to a given address, where messages were later aggregated into a longer document and sent back to the participants. In these messages, men and higher-profile members of the community dominated the discussions and engaged in more assertive behaviors when compared with women and lower-profile individuals. Another study found that college students' online discussions were dominated by male students (Carr, Cox, Eden, \& Hanslo, 2004), with the average number of turns taken in chat conversations being $18.5 \%$ higher for male than female students. In addition, female students focused more on collaboration and community building in their conversations, while messages from men included more adversarial styles of communication.

When gender equality in participation has been demonstrated in prior computermediated communication (CMC) literature, the online environment often explicitly included themes of inclusiveness in class discussions (Prinsen, Volman, \& Terwel, 2007). For example, McConnell (1997) explicitly discussed and encouraged equitable contributions from students during the CMC task. Given that the Wikipedia gender gap remains pronounced despite the inclusion of equality as part of the Wikipedia mission statement, specific interventions designed to model the value of social justice on Wikipedia may be needed to facilitate more widespread equality. 
Potential explanations for the Wikipedia gender gap ascertained from prior literature have included intrinsic factors (e.g., personality factors, avoidance of contentious environments), extrinsic factors (e.g., inequality in leisure activity, harassment towards women), and factors that are a combination of both (e.g., perceptions of other editors). Well-controlled research could disentangle these potential explanations in order to identify specific mechanisms underlying the Wikipedia gender gap.

\subsection{Current Study}

Research is needed to more comprehensively understand the barriers to collaborative editing that women face. Likely due to the difficulty of manipulating noneducational online environments, none of the prior studies investigating the Wikipedia gender gap have used experimental research methods to identify specific variables that may differentially impact the collaborative editing behaviors of women and men. On Wikipedia in particular, there are limited opportunities for researchers to manipulate the online space to study these mechanisms in the context of actual editing behaviors. Consequently, the current study used a simulated, public collaborative environment to assess editing behaviors in a controlled environment.

Instead of editing on Wikipedia, participants in the current study edited a Word document, in which they were told that four of their peers had previously edited the document. Participants saw the edits of their peers through the use of tracked changes, where each peer was given a unique username. All of the peer edits were actually conducted by the research team, allowing the team to manipulate and control the usernames and contributions of the peer editors. Participants were also told that they would be contacted in 1-2 weeks and given the choice to further edit the document after 
others had made additional edits (see Procedures section for manipulation details).

In an effort to simulate the public nature of Wikipedia and other online collaborative spaces, participants were told that the document would be publicly posted in their college newsletter and that the research team would be creating a website on cyberbullying (the topic of the editing essay) where the edited document would be featured for others to read. Through an experimental manipulation, offline spaces such as Word documents with tracked changes might facilitate similar patterns of communication to those that occur on Wikipedia. Similarly, college students from a public university were chosen to take part in the collaborative editing task as students are increasingly accessing collaborative, online environments inside and outside of college classrooms (see Shane-Simpson et al., 2015),

This study examined gendered editing behaviors in a public, collaborative editing environment. The following research questions were addressed:

1. Is gender identity related to unique patterns of editing in the context of public, collaborative editing tasks?

2. Does experience with online editing, civic attitude and behavior, or pro-social behavior underlie gender differences in students' editing behaviors?

3. Do students have expectations about how peer editors will evaluate their work that are attributable to the gender of the other editors?

\subsection{Material and Methods}

\subsection{Participants}

A total of 203 participants were recruited for this study from a subject pool at a large university in exchange for three research credits. Three participants did not 
complete the activity (i.e. did not add or delete any text when asked to edit the document) and were excluded from analyses. The students at this campus were diverse with many working-class students (45\% of the undergraduates are low-income). Participant ages ranged from $18-41(M=19.59 ; S D=3.40)$, with 96 participants who identified as male and 97 as female ( $n=7$ chose not to answer).

Participants' ethnicities were not mutually exclusive categories and included $30 \%$ $(n=60$ out of 200) Caucasian/White, 27\% Hispanic/Latino, 13\% African American/Black, 10\% other ethnicity (i.e., mixed), 8\% Asian, 3\% Middle Eastern, and $2 \%$ as Indian ( $n=14$ chose not to answer).

\subsection{Procedure}

After providing consent to participate, each student completed a paper-based demographics form, was instructed to engage in the editing task for 30 minutes, and was then asked to complete an online survey. After completing the demographics form, participants were shown a computer screen with a half-written draft of an essay on cyberbullying. The researcher's script explained that the essay had already been edited by the participant's peers, the participant would have an opportunity to make further edits in the next few weeks or so, and the final version of the essay would be posted publicly to the college newsletter and onto a website that the research team was creating about cyberbullying (see Appendix A). The researcher also explained to the participant how the tracked changes were used in the Word essay and how the participant could further edit the document using tracked changes and comments. As a comprehension check, the researcher asked the participant to make a few practice changes in the essay (i.e., could you add a comment?). 


\subsection{Measures}

\subsubsection{Demographics form}

Participants were asked to complete a short, paper-based survey of demographic information (see Appendix A). This form was described as an opportunity for participants to generate a profile that would be connected with their edits, where the peer editors and public readers of the essay would be able to view their profile information. Participants were asked whether they wanted personal attributes, such as ethnicity, connected with their essay edits; this opportunity to choose information to include in their profile was designed to mirror Wikipedia. While Wikipedia editors can choose (or not choose) to use a username and profile, many repeat editors develop a profile with some information about themselves in order to establish credibility on the potentially anonymous site. A total of 41 out of 193 participants ( $n=7$ did not answer) did not want their age connected with their edits, while 65 out of 190 ( $n=10$ did not answer) did not want their ethnicity connected with their edits. Similarly, 56 out of 189 ( $n=11$ did not answer) participants did not want their major connected with their edits.

Participants were also asked for their gender and username, which would be linked with their essay edits. Participants were not given an option about whether they wished to link their gender with their profile in order to highlight a connection between gender and usernames. All of the participants created a username, although some usernames were more anonymous than others (e.g., anonymous 2). However, due to an administration error, the first 40 participants in this study did not receive all aspects of the intended manipulation. Although all participants were asked to chose a unique username to be linked with their edits, the username for each of the first 40 participants was not 
linked with their edits (via tracked changes). Consequently, these participants did not see their chosen username when editing and instead saw a random username (often a female researcher). Given that their own chosen username was not linked with their editing behaviors for these 40 participants, the intended experimental manipulation was unlikely to be successful for them as they would have no reason to expect that the other editors' usernames in the document were not also arbitrary. Indeed, the 40 participants who did not receive the correct manipulation did not differentiate between the other editors based on their usernames, as will be demonstrated in the results section. Therefore, we first evaluated whether the fidelity of administration impacted findings, and when it did, we focused the analyses on the 160 participants whose usernames were correctly linked with their edits.

The demographics form also prepared participants to begin considering what they knew and felt about cyberbullying, the topic of the essay they were asked to edit, through short writing prompts.

\subsubsection{Online survey}

The following variables were assessed via an online survey, which was administered through Qualtrics survey software (see Appendix B).

\subsubsection{Civic attitudes and behaviors}

Participants' civic attitude and civic engagement were assessed through items developed by Raynes-Goldie and Walker (2008) and modified by the current researcher to reflect modern online environments. For example, an original item stated: I read news online. This statement was then modified to include current SNSs: I read news online through a news site or through a social media network (Facebook, Twitter, etc.). 
Responses were given on a 4-point Likert scale ranging from NA/Never (1) to Often (4), and items from this measure were totaled into a Civic Total score. Items in this total scale were moderately high in internal consistency $(\alpha=.75)$.

\subsubsection{Pro-social behaviors}

Pro-social behaviors were assessed using 13 of the 23 items in the original prosocial measure developed by Carlo and Randall (2002). This subsection of items was chosen based on their perceived relevance for the college-aged population from which the sample was drawn. Sample items included, 1) I help people best when I am being watched, and 2) it is most fulfilling to me when I can comfort someone who is very distressed. Responses were provided on a 5-point Likert scale ranging from describes me greatly (5) to does not describe me at all (1). The Cronbach's alpha for these items was moderately high at $\alpha=.77$.

\subsubsection{Internet and Wikipedia use}

Participants were asked how much time they spent on the Internet (more generally), how much time they spent on Wikipedia, and their level of experience with online editing (see Appendix B). Item responses for these two questions ranged from I'm always on Wikipedia/the Internet (5) to Less than an hour (1).

\subsubsection{Attitudes and stereotypes about peer editors}

Participants' pre-conceived attitudes and stereotypes about identity characteristics, such as gender, were assessed through a series of questions asking participants to describe their peer editors. Participants were asked the gender of the peer editor and how they felt each editor would evaluate their own work. These questions 
asked about each of the four peer editors: MrFootballFan, MsTrouble ${ }^{1}$, Cheerios4Life, and AnonymousOne. These four peer editor names were chosen after piloting a longer list of potential names with a group of undergraduate, graduate, and faculty researchers to identity a feminine name, masculine name, gender-neutral name, and anonymous name.

\subsubsection{Collaborative essay editing}

The primary researcher wrote the collaborative editing essay under the disguise of the peer editor pseudonyms. Content and writing style for the essay were based on the researcher's prior teaching experiences in assigning a similar essay during repeated sections of a Human Development class in the same university system. Although direct text was not directly taken from prior students, the work of prior students was used as a guide to the types of references, writing style (e.g., sentence structure), and breadth of coverage that was consistently turned into the researcher each semester. As such, the essay was meant to reflect the varying skill levels and limited breadth of content coverage often found in high-stakes undergraduate student writing assignments.

The essay included four sections: Definition and Prevalence (fact-based section), Subjective Experiences and Interpretation (opinion-based section), Conclusion, and References. This report focuses on edits in the fact-based section, which is the most akin to Wikipedia. Each participant was randomly assigned to one of two peer feedback versions of the essay. The first version included peer edits that were constructive in nature. For example, a peer editor commented that an edit, sounds important, but might be better in the last section of the paper. Each comment in the constructive feedback

\footnotetext{
${ }^{1}$ Each of the peer editor usernames was collaboratively identified as feminine, masculine, gender-neutral, or anonymous by the research team. However, the primary researcher notes that the username MsTrouble may be a particularly charged username due to the Trouble aspect of the name.
} 
essay began with a positive affirmation and then provided a suggestion for improving the essay. The second version of the essay only included neutral feedback from the peer editors, neglecting the positive affirmation component. Contrasting the peer editor comment previously described, a comment in the neutral feedback essay version might state, this might be better in the last section of the paper.

The peer editors allegedly made eight comments in each essay and twelve additional, in-text edits. In order to ensure that the overall pattern of editing behaviors and perceptions of the editors was attributable to each peer editor's name rather than to the type of edits made, a Latin square was used to counterbalance the specific peer edits and original text additions assigned to the peer editors. This resulted in four conditions for each of the two versions of the essay ( 8 essays total). For example, the added text from MrFootballFan in essay condition one was rotated in essay condition two, so that MsTrouble added that text in essay condition two. Whether the original peer contribution added fact or subjective information was also sequenced across the peer editors so that each editor contributed the same overall amount of fact and subjective information but in different essay sections, depending on the condition. Finally, content added to the original essays was also rotated so that each peer editor added at least a few sentences to each essay section. See Figures 1-8 for examples of each condition and version of the fact-based section of the essay.

[Figures 1-8]

As can be seen in the aforementioned figures, deletions from the essay and comments added to the essay were clearly linked with the name of the peer editor who allegedly produced them. However, additions of text are far less visible as belonging to a 
specific person in tracked changes. The relatively high number of edits and comments made by the peer editors in each section of the essay coupled with the general lack of clear demarcation of direct additions in tracked changes likely resulted in participants' not identifying which of the peer editors allegedly added original text to each section. Consequently, participants may have felt that a peer editor did not contribute to a given section, unless that peer editor made deletions or comments.

\subsection{Analytic Plan}

Each edited essay was coded to identify the number of characters added and deleted, in addition to the number of comments added. A coding dyad collaboratively analyzed a subset of essays (approximately five essays) to check for agreement and consistency in the procedures. As a final step to calculate reliability, each coder in the dyad independently analyzed $20 \%$ of the data to calculate the percent agreement (40 essays). This consensus coding method resulted in a $100 \%$ percent agreement. One coder then independently coded the number of addition and deletions for each essay section and the number of comments in the fact-based section.

Descriptive analyses revealed excessive skew in a number of variables, square root transformations (for additions, deletions, and comments) and log transformations (for age) were used to correct skew. Descriptive statistics are reported with nontransformed editing variables for ease of interpretation. Age was included as a covariate in models when it was correlated with the outcome variables. Independent samples t-tests with the entire sample were used to examine potential gender differences in personality characteristics and Internet experience. Analyses of editing behaviors were conducted using multivariate general linear models with essay condition, essay version, and gender 
as independent variables and transformed additions and deletions in the Definition and Prevalence section of the essay as dependent variables. Participants' perceptions of peer editors' gender were analyzed using chi square tests. Participants' perceptions of peer editors' evaluations of their own work were evaluated using multivariate general linear models with expectations about how each peer editor would evaluate their work as the dependent variables. The usernames, essay version, essay condition, and gender were included as the independent variables and the total quantity of the participants' in-text edits as a covariate. Analyses were conducted in SPSS 22 and significance was evaluated at the $\leq .05$ level.

\subsection{Results}

\subsection{Gender Differences in Key Variables}

Independent t-tests were used to identify whether men and women differed in their age, civic total scores (civic attitudes and behaviors), pro-social behaviors, Internet use, Wikipedia use, and online editing experience. Each of these factors could potentially influence participants' editing behaviors and were chosen as key factors that might influence a relationship between Wikipedia editing and gender based on prior literature. These analyses identified a gender difference in civic total scores $(t(190)=2.37, p=$ .019; Table 1), favoring men. A gender difference in pro-social behaviors was also observed $(t(190)=-2.79, p=.006)$, favoring women. There were no gender differences in age, Internet use, Wikipedia use, and editing experience $\left(p s>.12^{2}\right)$.

\subsection{Editing Behaviors, Essay Condition, and Gender}

\footnotetext{
${ }^{2}$ The same gender differences were observed if analyses focused only on the 160 participants whose usernames were linked to their edits.
} 
Analyses focused on editing behaviors in the fact-based section of the essay (Definition and Prevalence). This particular essay section was chosen due to its more Wikipedia-like focus on fact-based information sharing in comparison with the other essay sections that included personal experiences rather than just facts (i.e., subjective information, conclusions). Table 2 illustrates how many of these participants were exposed to each of the four conditions of the neutral and the constructive version of the essay.

\section{[Table 2]}

A multivariate general linear model examined predictors of characters added and characters deleted in the fact-based section of the essay (additions and deletions were the two dependent variables). Between-subjects independent variables in this model included fidelity of the experimental manipulation (whether or not the participant's username was linked to their edits), the essay version (Constructive or Neutral), self-reported gender (male or female), and essay condition (1-4 Latin square rotation of edits made by peer editors). Age was included as a covariate in this model due to an observed relationship between characters added to the essay and age $(r(149)=.180, p=.03)$.

The initial analysis revealed an interaction between additions and deletions in the essay and fidelity of administration, essay condition, and essay version $(F(3,159)=$ $3.42, p=.02$ ). This interaction provided evidence that fidelity of administration impacted findings. Therefore, we focused subsequent analyses of editing behaviors on the 160 participants whose usernames had been effectively linked to their edits.

This analysis revealed a main effect of characters added and characters deleted $(F$ $(1,133)=11.71, p<.001) ;$ participants added more characters $(M=243.10, S E=18.62)$ 
than they deleted $(M=67.77, S E=8.39)$. A main effect of gender was also observed $(F$ $(1,133)=6.82, p=.01)$; men $(M=122.44 S E=15.93)$ altered the text less than women $(M=188.42, S E=17.10)$. An interaction between characters added and characters deleted and age was observed $(F(1,133)=15.61, p<.001)$; age was positively associated with characters added $(r(149)=.180, p=.03)$ and was not associated with characters deleted $(p=.22)$. An interaction between gender, essay condition, and essay version was also observed $(F(3,133)=3.99, p=.01)$.

When the data was split by essay condition, the interaction between gender and essay version (Constructive versus Neutral) remained only in the second essay condition $(F(1,31)=10.01, p=.003)$. This interaction was not apparent in the first $(p=.35)$, third ( $p=.36)$, or fourth essay condition $(p=.68)$. As discussed in the Methods, the female peer editor had written some of the original text in this section, but did not delete text in it or comment upon it. Therefore, it appeared that the female editor had not contributed to the fact-based section of essay condition two.

The second condition data was further split by essay version (Constructive versus Neutral) to evaluate if men and women differed in editing behaviors based on the type of essay they were given. Interactions between gender and characters added and deleted were observed in the neutral $(F(1,15)=5.09, p=.04)$ and in the constructive version $(F$ $(1,15)=4.77, p=.045)$ of the essay. However, the pattern of this interaction was different for each version of the essay. In the neutral version of essay condition two, a trend toward men adding more characters $(M=343.40, S E=103.09)$ than women was observed $(M=161.25, S E=82.06 ; p=.07)$. In contrast, in the constructive version of essay condition two, women $(M=358.43, S E=104.10)$ added more characters than men 
$(M=125.82, S E=45.05 ; F(1,15)=7.07, p=.02)$. No gender differences in characters deleted were observed ( $p$ s > .73). Therefore, women added more content than men in the fact-based portion of an essay when it lacked a visible female peer editor but contained positive affirmations from male, anonymous, and gender-neutral peer editors. In addition, there was a trend toward men adding more characters than women in the absence of a visible female peer editor when positive affirmations were also absent.

In order to address our second aim, we also entered characteristics that had differed between genders from the independent t-tests (i.e., civic total scores and prosocial behaviors) into the aforementioned model. The findings from the aforementioned analyses without these covariates remained apparent: a greater number of additions than deletions $(F(1,131)=5.96, p=.02)$, a main effect of gender $(F(1,131)=7.46, p=.01)$, an interaction between additions and deletions and age $(F(1,131)=13.41, p<.001)$, and an interaction between gender, condition, constructive/neutral, and additions/deletions ( $F$ $(1,131)=4.10, p=.01)$ An additional interaction (not observed in the previous model) between gender and the number of additions and deletions was also observed $(F(1,131)$ $=8.00, p=.01)$. Follow-up analyses revealed that women $(M=282.87, S E=31.95 ; p=$ $.07)$ added more characters than men $(M=193.71, S E=22.09 ; F(1,133)=7.51, p=.01)$, but men and women did not differ significantly in characters deleted $(p=.14)$. An interaction between pro-social behaviors and the number of additions and deletions was also observed $(F(1,131)=12.29, p=.001)$. Post-hoc analyses revealed that participants who self-reported higher pro-social behaviors deleted more text $(r(158)=.21, p=.01)$; no associations between pro-social orientation and adding text were observed $(p=.15)$.

\subsection{Comments Added, Essay Condition, and Gender}


Another general linear model, with the same independent variables, was run with the number of comments added to the fact-based essay section as the dependent variable. Age was added as a covariate in this model due to a trend toward a relationship between number of comments added in the fact-based essay section and age $(p=.053)$. Only age was (negatively) associated with the number of comments $(F(1,133)=4.54, p=.04)$.

\subsection{Perceptions of Peer Editors}

The following analyses explored how participants viewed the peer editors in the context of gender and essay condition.

\subsubsection{Perceptions of the gender of peer editors}

Not surprisingly, $94.5 \%$ of participants $(n=188$ out of 199 ; one participant did not answer these questions) identified MrFootballFan as male, 3.5\% of participants selected female, and $2 \%$ were undecided. A binomial test confirmed that MrFootballFan was identified as male significantly more often than female $(p<.001)$. The majority of participants identified MsTrouble as female (88.4\%, $n=176 ; p<.001)$, although $4.5 \%$ selected male and 7\% were undecided. A binomial test confirmed that MsTrouble was identified as female significantly more often than male $(p<.001)$. In regards to Cheerios4Life, participants were split between identifying this peer editor as male $(43.2 \% ; n=86)$, female $(42 \% ; p=.94)$, and undecided $14.6 \%$. The final peer editor, AnonymousOne, was most often identified as male $(60.8 \%, n=121)$, although $26.1 \%$ identified AnonymousOne as female, and $13.1 \%$ were undecided. A binomial test confirmed that AnonymousOne was identified as male significantly more often than 
female $(p<.001)$. There was no difference in how male and female participants identified AnonymousOne $(p=.87)^{3}$.

\subsubsection{Perceptions of how peers would evaluate one's own editing}

A multivariate general linear model examined if participants felt that the four peer editors would evaluate their work differently depending on fidelity of administration, participant gender, essay condition, essay version, and their own contributions to the essay. As discussed in the Methods, the actual contributions of each editor were counterbalanced across essays so any effects of editor name were attributable to the name itself rather than the editor's behaviors. The dependent variables in this model were participant perceptions of how each of the peer editors' would rate the participant's own editing, while independent variables included whether or not the manipulation was enacted as planned, essay condition, gender, and essay version. Age was unrelated to evaluations of other editors' perceptions so it was not included in this model. Each participants' edits (in-text additions and deletions) to the essay were included as covariates in the model since editors' perceptions of one's work is likely to be influenced by the amount of work one puts into the essay.

In this initial model, an interaction between fidelity of administration and perceptions of the peer editors was observed $(p=.02)$. As expected, post-hoc analyses revealed that participants only expected different editors to evaluate their work differently when the participant's name was correctly linked to the participant's edits ( $F$ $(3,133)=2.73 ; p=.046)$. No main effect of editor was observed when the participant's name was not linked to his or her edits $(p=.47)$. Therefore, we focused the following

\footnotetext{
${ }^{3}$ This pattern of findings in the full sample is unchanged if analyses focus only on the 160 participants whose usernames were linked to their edits.
} 
analyses on the 160 participants whose names were effectively linked to their editing behaviors. Post-hoc tests investigating the aforementioned main effect of editor among the 160 participants who received the appropriate manipulation did not reveal significant differences between particular editors ( $p$ s > .13).

However, an interaction between peer editor evaluations, gender, and essay version (constructive vs. neutral) was also observed, $(F(3,133)=4.11 ; p=.01)$. The data was split by gender to examine the relationships between these variables. An interaction between editor perceptions and essay version remained significant for women $(F(3,58)=3.16, p=.03)$ and did not remain for men $(p=.15)$. When the data from women was then split by essay version, a main effect of editor was observed in the constructive $(F(3,27)=3.22, p=.04)$, but not the neutral condition $(p=.39)$. In the constructive essay version, women reported that Cheerios4Life $(M=4.04, S E=.15)$ would evaluate their work more positively than AnonymousOne $(M=3.75, S E=.14$; $p=$ $.02)$.

\subsection{Discussion}

Unexpectedly, women added more overall text to the essay than men. However, in the editing environment that was most akin to Wikipedia (i.e., neutral feedback from peers and lacking a visible female editor in the fact-based section of the essay), men trended toward adding more characters to the fact-based section of the essay than women. In contrast, women added more characters than men to the constructive version of this apparently male-dominated section of the essay. These findings suggest that women, even female college students who the current findings suggest may be more motivated overall to contribute to collaborative academic projects than their male peers, may be 
disinclined to edit collaboratively in groups without visible female peers when the group communication pattern is less encouraging.

The high proportion of anonymous editors in many online spaces (e.g., Qian \& Scott, 2007) might further discourage women from participating by making collaborative editing environments like Wikipedia appear even more male-dominated and critical than they are. Indeed, participants in the current study were more likely to view AnonymousOne as male than female. Women who edited essays with constructive peer editors also reported that the gender-neutral peer editor, Cheerios4Life, would evaluate their work more positively than AnonymousOne.

\subsection{Gender, Group Composition and Editing Behaviors}

In stark contrast to the gender gap favoring men on Wikipedia, women edited more overall then men in the current study. Although most studies examining computermediated communication (CMC) in educational contexts have aligned with the Wikipedia gender gap in demonstrating that men tend to dominate mixed-gender online collaborations (reviewed by Prinsen et al., 2007), a few studies have revealed that women contribute more frequently than men in some mixed-gender online contexts, particularly relatively small group collaborations that extend across time (e.g., His \& Hoadley, 1997, McConnell, 1997). These findings findings suggest that the positive feedback that often arises when peers have opportunities to develop supportive relationships with one another may encourage women to participate actively in computer-mediated collaborations.

In contrast, the male dominance that is found in many asynchronous $\mathrm{CMC}$ environments (e.g., Carr, Cox, Eden, \& Hanslo, 2004; Selfe \& Meyer, 1991) might be particularly apparent in Wikipedia-like collaborative spaces (or male-dominated spaces 
wherein feedback tends to lack positive affirmations). Indeed, the specific condition in the current study that most directly mirrored Wikipedia (e.g., condition 2 of the neutral version of the essay), wherein both visible female role models and encouraging feedback were not explicitly present, was the only context in which men trended toward editing more than women.

Consistent with prior Wikipedia research (using surveys and analyses of talk pages), women preferred to add content in the positive, more supportive collaborative environment (Collier \& Bear, 2012; Laniado et al., 2012) when compared with the more neutral environment in the apparent absence of another female peer editor. This was not a general pattern, this finding was found in a specific essay condition that was most similar to the actual, male-dominated, Wikipedia editing environment (condition two). Even though the female peer editor had provided some of the original text in this essay condition, the participants in the current study likely overlooked her contributions as a result of the limited cues as to who provided the original text in tracked changes and the relatively high number of (more visible) deletions and comments made in the essay.

These findings validate the results from Laniado and colleagues (2012) who found initial evidence of emotional homophily on Wikipedia, where editors tend to engage with others who exhibit similar patterns of communication. The absence of visible other women in the second essay may have changed how women and men engaged with the editing task. Adding content into an essay opens one up to criticisms from the collaborative community, which might prevent one from contributing due to the potential for criticism. This might be particularly salient in more neutral versus positive environments. Female participants may have felt that they would be targeted with such 
criticism due to the absence of other female voices in the text and the relative lack of supportive comments encouraging participation. Men may have felt more comfortable editing in the neutral environment given the presence of another male editor with the likelihood that they, like participants overall, viewed the anonymous editor as also male. Future qualitative research should explore the editing choices women and men make and why they make them in relation to group composition and type of feedback.

The current findings further highlight the important role of positive peer editor behaviors and an overall positive editing environment in encouraging novice Wikipedians to contribute to collaborative editing. Crowston and Fagnot (under review) clearly identified the significance of editing stage, in which new editors require an awareness and understanding of the editing content, but also require positive evaluations from peers. This need for a supportive space may be particularly salient for novice female editors. As such, Wikipedia and other collaborative editing environments should strongly consider methods that effectively support novice editors and encourage sustained engagement.

It is important to note that male and female college students in the current study did not differ consistently in the extent to which they contributed to the fact-based portion of the essay. While facts are traditionally thought to cater more strongly towards men than women in certain environments (e.g., Facebook; Yang, Brown, \& Braun, 2013), women edited more overall than men in the fact-based environment in the current study. These results highlight a potential shift in masculine and feminine communication styles in collaborative spaces. The prior literature has indicated historical trends from gender differences to more similarities between the genders in offline spaces (Hyde, 2005). This has been reflected in re-validation attempts of Bem's Sex Role Inventory which suggest 
that the historical differences between masculine and feminine traits found when the measure was originally created and validated in 1974 may lessen over time in favor of more gender-neutral behaviors (see Twenge, 1997).

These results also suggest that the ways in which researchers define and explore gender in certain online spaces may require a more flexible-identity or dual-identity approach, where individuals adopt both masculine and feminine roles (Martin, Cook, \& Andrews, 2016). Certain environmental conditions may encourage editors to contribute in different ways, and male and female college students may require unique online environmental conditions for effective editing to occur.

Familiarity with a given technology and the editing skill of the editors may also impact editing behaviors. Although technology and editing skill-level were not directly assessed in the current study, the college students in this study were likely of a lower-skill level and many of them had probably not previously edited on Wikipedia (see ShaneSimpson, Che, \& Brooks, 2016). In fact, the current participants indicated limited familiarity with Wikipedia and online editing, more generally. Prior literature has revealed that gender differences in editing are not apparent among lower-activity Wikipedia editors (Antin, Yee, Cheshire, \& Nov, 2011) and are more apparent in higherskilled editors (Hargittai \& Shaw, 2015). The current results extend the findings of Hargittai and Shaw (2015) to suggest that the gender gap in collaborative editing may persist for lower-skilled editors in very specific environmental circumstances (e.g., neutral editing environments that lack visible female peer editors). As such, future studies should consider how skill level might impact the editing behaviors of Wikipedians with varying skill levels in specific contexts. 


\subsection{Personality Characteristics Associated with Editing Behaviors}

Men reported heightened civic attitudes and behaviors, indicating increased interest in contributing to the greater good. In contrast, women reported greater pro-social behaviors, or the desire to help others. These findings suggest that men and women may have similar, but slightly different, motivations to contribute through public editing sites. Civic orientations can be broadly conceptualized as behaviors and attitudes that aim to improve society while pro-social behaviors tend to be more focused on helping specific other people. Research has found that editors on Wikipedia have a heightened desire to give back to the greater good (Baytiyeh \& Pfaffman, 2010; Cho, Chen, \& Chung, 2010; Jullien, 2012; Kuznetsov, 2006; Nov, 2007; Okoli et al., 2012; Shroer \& Hertel, 2009). However, only pro-social behaviors (and not civic attitudes) were associated with editing behaviors in the current study. This likely reflects a key difference between contributions to collaborative enterprises that one seeks out (e.g., edits on Wikipedia itself) and contributions one is asked to do for course credit (e.g., the current study).

Nevertheless, pro-social behaviors (more strongly expressed by women) were associated with higher levels of deleting of others' text. This association may arise because a focus on others in order to help them is central to the definition of pro-social behaviors. As such, deleting text could be viewed as a pro-social grooming behavior wherein one removes flaws from others' writing. This finding suggests that analyses of contributions to Wikipedia should focus not only on what people add, but also on what they take away. Although neither self-reported pro-social behavior nor civic behaviors and attitudes accounted for relationships between gender and editing behaviors in the current study, these findings suggest that women's greater interest in helping specific 
others (heightened pro-social behaviors) could be used to encourage them to edit on Wikipedia. Editing interventions could be framed around helping specific individuals and or marginalized groups (e.g., developing information that members of such groups could use to advocate for needed resources) in order to motivate potential female editors who may be more interested in helping specific people than in contributing to more abstract representations of the public good.

\subsection{Perceptions of Peer Editors and Editing Behaviors}

Although the actual contributions of the peer editors was counterbalanced, the anonymous peer editor was most often identified as male; this may reflect current westernized cultural norms towards the identification of other as male versus female. Building on research findings that novice editors need to feel valued by others in the collaborative community (Crowston \& Fanot, under review), individuals interested in contributing to a Wikipedia article may refrain from editing due to an online environment that is heavily anonymous, and assumed to be male-dominated. New editors may feel that their edits will be reverted or criticized by others, thereby leading them to refrain from contributing to the site. Although the current study did not measure gender differences in editing comfort, prior research suggests that women may feel less comfortable editing the work of others (Collier \& Bear, 2012), and this may be exacerbated if those others are unknown. Therefore, the nature of the peer editor environment likely contributes to specific types of editing behaviors.

Overall, there is a need to cultivate more positive peer collaborative spaces, particularly where anonymous users are widespread (e.g., Wikipedia). These combined results highlight how certain characteristics of editing environments, such as the presence 
of similar-gender others or the feedback provided by others, might influence how editors engage in peer collaborative spaces. Furthermore, the ways in which editors perceive their peers (e.g., anonymous, gender neutral, gendered) may also impact how they edit.

\subsection{Limitations}

While the current study expanded the literature on collaborative editing environments, specifically for undergraduate populations, this study also included several limitations that should be addressed in future research. The eight versions of the essay were created in such a way that the edits made by peers were counterbalanced throughout each of the essays. Each peer editor was also represented in their "initial edits" on the essay, or the sections of the essay where they added actual text versus comments or revisions to the work of others. In order to effectively represent each of the peer editors in these initial essay contributions, each of the peer editors did not make revisions to the sections of the essay where they had made their initial contributions. Consequently, and likely due to the relatively high number of edits made in each section by the peer editors, participants in this study may not have identified which of the peer editors had written the initial text for each section. This resulted in the perceived "absence" of a peer editor from each of the sections (the section they initially wrote). Similarly, the chosen peer editor usernames may have impacted the findings. A counterbalanced array of different names for each identity category (male, female, anonymous, and gender-neutral) was not used to represent the construct that each name was meant to represent. Therefore, peer ratings may reflect the specific username itself and not the perceived gender of the peer editor.

In regards to inferences drawn from this study, the use of a simulated collaborative editing task differed from the true Wikipedia environment, specifically in 
regards to lacking the cultural norms, nuanced peer editor experiences, and technological barriers on Wikipedia. Wikipedia is a culturally laden environment with a substantial history of loyal contributors, who are relatively understudied in the current research. Participants who edited the collaborative Word document received course credit for their participation and thus did not demonstrate the intrinsic motivation to edit that Wikipedians exhibit or the reciprocal peer feedback environment that Wikipedia allows.

The editing task was similar to Wikipedia in that it required participants to generate a username that was linked with their edits, participants were told that the document would be made publicly available, and participants independently added information into the document (versus team-based editing). However, the editing task was dissimilar in requiring participants to create a paper-based profile (versus an online profile). This demographic form was designed to reflect the types of information that Wikipedians can choose to provide via their user pages. Participants were asked to select any username, which could be gendered or not, similar to the Wikipedia environment. However, participants were directly asked for their gender and would not have been asked their gender on the actual Wikipedia space. Furthermore, participants in the current study were not asked whether they wanted their gender linked with their editing, which may have helped to clarify how editors self-present their gender online. Future research should use a simulated online environment that asks participants to fill in their entire profile at the level that participants feel comfortable doing so.

The current study utilized a Word document for the editing task due to a lack of student familiarity with wikis and wiki-like environments (see Shane-Simpson, Che, \& Brooks, 2016). However, future studies should strongly consider using a Wikipedia or a 
Wikipedia-like environment (e.g., Wiki) to more closely model the interactions that might occur through the English Wikipedia. Wikis are collaborative systems, where editing can occur amongst more than one user on a site; Wikipedia is one of the more complicated wiki environments. The use of Wiki environments would allow assessments of online collaborative behaviors in more naturalistic settings involving real-time feedback from peers.

\subsection{Conclusions}

In the current study, the Wikipedia-like editing condition, wherein female peer editors were underrepresented and peer feedback was neutral, men (trended towards) adding more content than woman. In contrast, women edited more in the fact-based essay condition lacking a visible female peer editor when peer editors modeled constructive feedback. Consequently, the presence of visible female editors on Wikipedia and broader encouragement of the use of constructive feedback may help to alleviate some of the current Wikipedia gender gap.

Participants in the current study more often viewed the anonymous peer editor as male and women in the more positive editing environment felt that their gender-neutral peer would evaluate them more positively than the anonymous peer. As such, the high proportion of anonymous editors found in some online environments, such as Wikipedia, may exacerbate the gender gap by creating the illusion (or perhaps reality) of a maledominated and overly critical editing environment.

These results highlight a need for further research to more clearly identify the reasons driving the gender gap on Wikipedia, as gender differences in collaborative editing behaviors appear to be influenced by both the composition of mixed-gender 
collaborative groups and the communicative norms that these groups use. Longitudinal research could elucidate how communicative norms develop on Wikipedia as different types of editors interact with one another in order to identify interactional patterns that empower women to engage more fully in the collection and dissemination of knowledge. 


\section{References}

Antin, J., Yee, R., Cheshire, C., \& Nov, O. (2011). Gender differences in Wikipedia editing. In Proceedings of the 7th International Symposium on Wikis and Open Collaboration (pp. 11-14). ACM.

Baytiyeh, H., \& Pfaffman, J. (2010). Volunteers in Wikipedia: Why the community matters. Education, Technology, and Society, 13(2), 128-140.

Bear, J. B., \& Collier, B. (2016). Where are the women in Wikipedia? Understanding the different psychological experiences of men and women in Wikipedia. Sex Roles, $74,254-265$.

Bittman, M., \& Wajcman, J. (2000). The rush hour: The character of leisure time and gender equity. Social forces, 79(1), 165-189.

Boneva, B. S., Kraut, R., \& Frohlich, D. (2001). Using email for personal relationships: The difference gender makes. American Behavioral Scientist 45(3), 530-549.

Carlo, G., \& Randall, B. A. (2002). The development of a measure of prosocial behaviors for late adolescents. Journal of Youth and Adolescence, 31(1), 31-44.

Carr, T., Cox, L., Eden, N., \& Hanslo, M. (2004). From peripheral to full participation in a blended trade bargaining simulation. British Journal of Educational Technology, 35(2), 197-211.

Cho, H., Chen, M., \& Chung, S. (2010). Testing and integrative theoretical model of knowledge-sharing behavior in the context of Wikipedia. Journal of the American Society for Information Science and Technology, 61(6), 1198-1212. 
Collier, B., \& Bear, J. (2012). Conflict, confidence, or criticism: An empirical examination of the gender gap in Wikipedia. In Proceedings of the ACM 2012 Conference on Computer Support Cooperative Work (pp. 383-391).

Comber C., Colley A., Hargreaves D. J. \& Dorn L. (1997). The effects of age, gender and computer experience upon computer attitudes. Educational Research, 9, 123-134.

Crowston, K., \& Fagnot, I. (under review). Stages of motivation for virtual voluntary teams online engagement.

Eckert, S., \& Steiner, L. (2013). Wikipedia's Gender Gap. Media (dis) parity: A gender battleground. Lanham, MD: Lexington Books, 87-98.

Fenstermaker, S., \& West, C. (2002). Doing gender, doing difference: Inequality, power, and institutional change. New York, NY: Routledge.

Gardiner, B., Mansfield, M., Anderson, I., Holder, J., Louter, D., \& Ulmanu, M. (2016, April 12). The dark side of Guardian comments. The Guardian. Retrieved from https://www.theguardian.com/technology/2016/apr/12/the-dark-side-of-guardiancomments

Ghavami, N., \& Peplau, L. A. (2012). An intersectional analysis of gender and ethnic stereotypes: Testing three hypotheses. Psychology of Women Quarterly, O0(0), 115.

Glott, R., Schmidt, P., \& Ghosh, R. (2010). Wikipedia Survey - Overview of Results. United Nations University, Collaborative Creativity Group. Retrieved from: http://web.archive.org/web/20110728182429/http://www.wikipediasurvey.org/do cs/Wikipedia_Overview_15March2010-FINAL.pdf 
Hargittai, E., \& Shaw, A. (2015). Mind the skills gap: The role of Internet know-how and gender in contributions to Wikipedia. Information, Communication, \& Society, 18(4), 424-442.

Herring, S. C. (2000). Gender differences in CMC: Findings and implications. Computer Professionals for Social Responsibility Journal, 18(1).

Herring, S., Job-Sluder, K., Scheckler, R., \& Barab, S. (2002). Searching for safety online: Managing" trolling" in a feminist forum. The Information Society, 18(5), 371-384.

Hill, B. M., \& Shaw, A. (2013). The Wikipedia gender gap revisited: Characterizing survey response bias with propensity score estimation. PloS one, 8(6), e65782.

Hyde, J. S. (2005). The gender similarities hypothesis. American Psychologist, 60, 581592.

Jullien, N. (2012). What we know about Wikipedia: A review of the literature analyzing the project(s). Retrieved from http://dx.doi.org/10.2139/ssm.2053597.

Kuznetsov, S. (2006). Motivations of contributors to Wikipedia. ACM SIGCAS Computers and Society, 36(2).

Lam, S. T. K., Uduwage, A., Dong, Z., Sen, S., Musicant, D. R., Terveen, L., \& Riedl, J. (2011). WP: Clubhouse? An exploration or Wikipedia's gender imbalance. In Proceedings of the $7^{\text {th }}$ International Symposium on Wikis and Open Collaboration (pp. 1-10).

Laniado, D., Kaltenbrunner, A., Castillo, C., \& Morell, M. F. (2012). Emotions and dialogue in a peer-production community: The case of Wikipedia. In Proceedings 
of the Eighth Annual International Symposium on Wikis and Open Collaboration (p. 9). ACM.

Leaper, C., \& Smith, T. E. (2004). A meta-analytic review of gender variation in children's language use: Talkativeness, affiliative speech, and assertive speech. Developmental Psychology, 40(6), 993-1027.

Martin, C. L., Cook, R. E., \& Andrews, N. C. (2016). Reviving androgyny: A modern day perspective on flexibility of gender identity and behavior. Sex Roles, 1-12.

Mass, P., \& Zelenkauskaite, A. (2016). Gender gap in Wikipedia: A cross language comparison. In P. Fichman \& N. Hara (Eds.), Global Wikipedia: International and cross-cultural issues in online collaboration. Lanham, MD: Roman \& Littlefield Publishing Group.

McConnell D. (1997). Interaction patterns of mixed sex groups in educational computer conferences. Gender and Education, 9, 345-363.

Nov, O. (2007). What motivates wikipedians?. Communications of the ACM, 50(11), 6064.

Okoli, C., Mehdi, M., Mesgari, M., Nielsen, F. A., \& Lanamaki, A. (2012). The people's encyclopedia under the gaze of the sages: A systematic review of scholarly research on Wikipedia. Retrieved from: http://ssrn.com/paper=2021326

Ortega, F., Gonzalez-Barahona, J. M., \& Robles, G. (2008). On the equality of contributions to Wikipedia. In Hawaii International Conference on System Sciences, Proceedings of the $41^{\text {st }}$ Annual (pp. 304).

Pande, M. (2011). Wikipedia editors survey: Results from the editor survey, April, 2011. Retrieved from: 
https://upload.wikimedia.org/wikipedia/commons/7/76/Editor_Survey_Report__April_2011.pdf

Prinsen, F. R., Volman, M. L. L., \& Terwel, J. (2007). Gender-related differences in computer-mediated communication and computer-supported collaborative learning. Journal of Computer Assisted Learning, 23, 393-409.

Qian, H., \& Scott, C. R. (2007). Anonymity and self- disclosure on weblogs.Journal of Computer-Mediated Communication, 12(4), 1428-1451.

Raynes-Goldie, K., \& Walker, L. (2008). Our space: Online civic engagement tools for youth. In W. L. Bennet (Ed.), Civic life online: Learning how digital media can engage youth (pp. 161-188). Cambridge, MA: The MIT Press.

Savicki, V., Kelley, M., \& Lingenfelter, D. (1996a). Gender and group composition in small task groups using computer-mediated communication. Computers in human behavior, 12(2), 209-224.

Savicki V., Kelley M. \& Lingenfelter D. (1996b) Gender, group composition, and task type in small task groups using computer-mediated communication. Computers in Human Behavior, 12, 549-565.

Selfe C. L. \& Meyer P. R. (1991) Testing claims for on-line conferences. Written Communication, 8, 163- 192.

Shane-Simpson, C., Brooks, P. J., Hotez, E., Sawyer, J., \& Dow, E. A. A. (2015). Webenhanced collaborative learning in undergraduate psychology courses: Examples using the ASD video glossary, CHILDES, and Wikipedia. In R.V. Nata (Ed.), Progress in education (volume 36). Hauppage, NY: NOVA. 
Shane-Simpson, C., Che, E., \& Brooks, P. J. (2016). Giving psychology away: Implementation of Wikipedia editing in an introductory human development course. Psychology Learning \& Teaching. DOI: 10.1177/1475725716653081

Shroer, J., \& Hertel, G. (2009). Voluntary engagement in an open web-based encyclopedia: Wikipedians and why they do it. Media Psychology, 12(1), 96-120.

Soukup, C. (1999). The gendered interactional patterns of computer-mediated chatrooms: A critical ethnographic study. The Information Society, 15, 169-176.

Tannen, D. (1991). You just don't understand: Women and men in conversation. London: Virago.

Thacker, S., \& Griffiths, M. D. (2012). An exploratory study of trolling in online video gaming. International Journal of Cyber Behavior, Psychology and Learning (IJCBPL), 2(4), 17-33.

Twenge, J. M. (1997). Changes in masculine and feminine traits over time: A metaanalysis. Sex roles, 36(5-6), 305-325.

Underwood J., Underwood G. \& Wood D. (2001) When does gender matter? Interactions during computer-based problem solving. Learning and Instruction, 10, 447-462.

Wales, J. (2016, January 15). Wikipedia's strength is in collaboration - as we've proved over 15 years. The Guardian. Retrieved from http://www.theguardian.com/commentisfree/2016/jan/15/wikipedia-israelpalestine-15-years-encyclopedia

Wikimedia Foundation Mission Statement. (2015, January 4). Retrieved from https://wikimediafoundation.org/wiki/Mission_statement

Yang, C.-C., Brown, B. B., \& Braun, M. T. (2013). From Facebook to cell calls: Layers 
of electronic intimacy in college students' interpersonal relationships. New Media \& Society, 1-19. 


\section{Appendix A}

\section{Demographic Form for Cyberbullying Essay}

Please take a few moments to fill out the following form. Note that you have the option to link your entire bio form profile with your edits, part of your profile with your edits, or to keep your profile separate from your edits (i.e., only username would be linked with your editing).

1. What is your ID?

2. What is your age?

Do you want to link your age with your edits?
$\circ$ Yes
○ No

3. What is your ethnicity?

Do you want to link your ethnicity with your edits?
○ Yes
○ No

4. What is your gender?
- Male
- Female
- Transgender or Gender Invariant
- Other (please explain)

5. What is your major?

Do you want to link your major with your edits?
○ Yes
o No

6. What is your GPA?

Do you want to link your GPA with your edits?
○ Yes
○ No

7. Would you like to provide any further information? 
8. Please choose a username that WILL BE linked with your edits. You can choose any username, ranging from your real name to any made up (anonymous) name. Others who view the essay will see your username linked with your edits.

What would you like to list as your username?

You're finished with the bio form portion of the study. The next few questions will help you to start thinking about concepts found in the essay you'll be editing.

9. Examples of cyberbullying include....

10. Cyberbullying is happening more and more online, especially on sites such as...

11. We can do a lot to prevent and intervene in attempts at cyberbullying. For example, we could....

12. I think cyberbullying is different from face-to-face bullying because.... (note - you may also argue that it is similar to face-to-face bullying)

You've reached the end of this portion of the study. Please let the researcher know that you're ready to start editing. 


\section{Information Provided about Writing Prompt}

We'd like you to engage in a collaborative editing assignment with other students from CSI. This Word document contains a draft of a paper on cyberbullying that you will be writing and editing with other students from CSI who are participating in this study. Other students have already contributed to the Word document by adding their writing directly to the paper and by editing their peers' work, as you will see in the tracked comments section. You and other participants in this study are working together to write an essay that defines and provides prevalence rates for cyberbullying (this should be factual), and then describes your subjective experiences and interpretations of cyberbullying.

The researcher illustrates how to view tracked comments and make changes in a Word document, if needed.

We'd like all of our student editors to come back to this document and make further edits if they see fit once all editors have had a chance to contribute.

Consequently, you'll be invited to make additional contributions or edits to the document in a few weeks. We're planning to submit this document to the CSI newsletter, in addition to posting the document on a website we are creating about cyberbullying. We want the strongest final paper possible. In order to help us achieve the best possible paper, we need you to add your own writing directly into the document, to make edits on others' work in track changes, and to review the edits made by others and if necessary respond to them. Please let us know if you need help figuring out how to add text or comments to the document.

In order to ensure that the factual portion of the essay is objective and well-cited, 
you can research online to find and cite sources in the essay. Make sure that you don't just copy word for word from the Internet without citing your sources. You can delete, modify, or add to the changes made by others. Please make sure that you use constructive feedback when leaving comments. You will be doing this editing task for 30 minutes. I'll be back to check in on you every 5 minutes or so. While you're participating in this study, be sure to focus on the task at hand. Please don't use social networks and please put away your phone while working on this paper.

Comprehension Check (ask each participant to answer before they start)

1. To check your understanding of the instructions, would you mind showing me how you would make an edit in tracked changes?

2. How would you make a comment?

3. Make sure that you are paying attention to who is editing in the document. I'd strongly encourage you to take a few notes about the other editors since I'll be asking you questions about them in the online survey.

4. And, what are you supposed to do for the next 30 minutes? 


\section{Appendix B}

Online Survey

Internet Use

1. On an average day, how much time do you spend on the Internet? (this may be via phone, tablet, computer, etc.)

- I'm always on the Internet

- More than 10 hours

- 5-10 hours

- 1-4 hours

- Less than an hour

Wikipedia Use

2. On an average day, how much time do you spend using Wikipedia?

- I'm always on Wikipedia

- More than 10 hours

- 5-10 hours

- 1-4 hours

- Less than an hour

3. What has been your experience with online editing?

- I have no experience

- Some experience (I've edited something online a couple of times)

- Moderate experience (I've edited online more than a few times)

- Very experienced (I edit online regularly

\section{Civic Attitudes}

4. I use web sites, online communities, or online tools (message boards, Facebook, Twitter, etc.) to discuss current events or issues of importance to me with my friends.

- Often

- Sometimes

- Rarely

- Never

5. I make it a priority to stay informed about current events or issues important to me.

- Often

- Sometimes

- Rarely

- Never

6. When I am with my friends or family I discuss current events or issues of importance to me. 
- Often

- Sometimes

- Rarely

- Never

7. I read news online through a news site or through a social media network (i.e., CNN.com, Times.com, Facebook, Twitter).

- Often

- Sometimes

- Rarely

- Never

Civic Behaviors

8. I attend protests or rallies.

- Often

- Sometimes

- Rarely

- Never

9. I create media online (i.e., podcasts, videos, blogs) to get the word out about an issue.

- Often

- Sometimes

- Rarely

- Never

10. I participate in online protests.

- Often

- Sometimes

- Rarely

- Never

11. I vote in elections.

- Often

- Sometimes

- Rarely

- Never

12. I spread the word about political issues and current news events online via my social media network (Facebook, Twitter, Instagram, etc.).

- Often

- Sometimes

- Rarely

- Never 
13. I contact politicians, governments, or authorities about issues important to me.

- Often

- Sometimes

- Rarely

- Never

Prosocial Behaviors

Please indicate how much east statement does or doesn't describe you.

100. I help people best when I am being watched.

- Describes me greatly

- Describes me well

- Somewhat describes me

- Describes me a little

- Does not describe me at all

101. It is most fulfilling to me when I can comfort someone who is very distressed.

- Describes me greatly

- Describes me well

- Somewhat describes me

- Describes me a little

- Does not describe me at all

102. When other people are around, it is easier for me to help people in need.

- Describes me greatly

- Describes me well

- Somewhat describes me

- Describes me a little

- Does not describe me at all

103. I think that one of the best things about helping others is that it makes me look good.

- Describes me greatly

- Describes me well

- Somewhat describes me

- Describes me a little

- Does not describe me at all

104. I get the most out of helping others when it is done in front of others.

- Describes me greatly

- Describes me well

- Somewhat describes me

- Describes me a little

- Does not describe me at all 
105. I tend to help people who are in real crisis or need.

- Describes me greatly

- Describes me well

- Somewhat describes me

- Describes me a little

- Does not describe me at all

106. When people ask me to help them, I don't hesitate.

- Describes me greatly

- Describes me well

- Somewhat describes me

- Describes me a little

- Does not describe me at all

107. I tend to help others, particularly when they are emotionally distressed.

- Describes me greatly

- Describes me well

- Somewhat describes me

- Describes me a little

- Does not describe me at all

108. It is easy for me to help others when they are in a dire situation.

- Describes me greatly

- Describes me well

- Somewhat describes me

- Describes me a little

- Does not describe me at all

109. Most of the time, I help others when they do not know who helped them.

- Describes me greatly

- Describes me well

- Somewhat describes me

- Describes me a little

- Does not describe me at all

110. I never hesitate to help others when they ask for it.

- Describes me greatly

- Describes me well

- Somewhat describes me

- Describes me a little

- Does not describe me at all

111. One of the best things about doing charity work is that it looks good on my resume.

- Describes me greatly 
- Describes me well

- Somewhat describes me

- Describes me a little

- Does not describe me at all

112. I feel that if I help someone, they should help me in the future.

- Describes me greatly

- Describes me well

- Somewhat describes me

- Describes me a little

- Does not describe me at all

Attitudes and Stereotypes about Peer Editors

For the following questions, please make an educated guess about some of the characteristics of your peer editors.

122. What is the gender of Mr FootballFan?

- Male

- Female

- Other (please specify)

123. How do you think Mr FootballFan will evaluate your work?

- Positively

- Somewhat positively

- Neutral

- Somewhat negatively

- Negatively

*Note that these Perceptions of Peer Editors questions were repeated for each for the peer editor usernames. 


\section{GENDERED COLLABORATIVE EDITING}

\section{Acknowledgements}

The authorship team would like to thank Ben Cheriyan, Juny Rhee, and Anthony Massa for their work on this study. In addition, we'd like to acknowledge Patricia J.

Brooks, Anna Stetsenko, Michael Mandiberg, and Ellen-ge Denton for their guidance and suggested revisions on the original dissertation, from which this work is derived. 
GENDERED EXPRESSION ONLINE

Table 1

Differences in Potential Editing Predictor Variables and Editing Behaviors Based on Self-Reported Gender

\begin{tabular}{llllll}
\hline Variable & Men $M(S D)$ & Women $M(S D)$ & t-test & p-value & $d f$ \\
\hline Age & $19.80(4.05)$ & $19.31(2.92)$ & .96 & .339 & 189 \\
Civic Total & $\mathbf{2 2 . 0 6 ( 4 . 5 2 )}$ & $\mathbf{2 0 . 6 3}(\mathbf{3 . 8 5})$ & $\mathbf{2 . 3 7}$ & $\mathbf{. 0 1 9}$ & $\mathbf{1 9 0}$ \\
Pro-Social Behaviors & $\mathbf{3 7 . 7 7}(\mathbf{7 . 6 3})$ & $\mathbf{4 0 . 8 6}(\mathbf{7 . 7 5})$ & $\mathbf{- 2 . 7 9}$ & $\mathbf{. 0 0 6}$ & $\mathbf{1 9 0}$ \\
Time Spent on Internet & $3.19(1.17)$ & $3.47(1.29)$ & -1.58 & .116 & 188 \\
Time Spent on Wikipedia & $1.25(.78)$ & $1.41(.84)$ & -1.33 & .184 & 190 \\
Online Editing Experience & $1.69(.83)$ & $-.34(.85)$ & .05 & .731 & 190 \\
Characters Added in Def & $208.21(230.22)$ & $303.16(287.15)$ & -2.54 & .012 & 183 \\
Characters Deleted in Def & $52.91(87.98)$ & $81.49(106.83)$ & -2.03 & .044 & 185 \\
Comments Added in Def & $.91(1.52)$ & $1.02(.99)$ & -.62 & .536 & 191 \\
\hline
\end{tabular}

Note. $N=96$ men, 96 women for each t-test, with the exception of age $(n=94$ men and 97 women). Def = Definition and Prevalence section of the essay. Age, Characters Added in Def, Characters Deleted in Def, and Comments Added in Def are untransformed variables. 
Table 2

Number of Participants in Each Essay Condition and Version

\begin{tabular}{lll}
\hline Essay Version & Essay Condition & Number of Participants \\
\hline Constructive & One & 25 \\
& Three & 24 \\
& Four & 26 \\
& & 26 \\
\hline Neutral & One & 26 \\
& Two & 24 \\
Three & 23 \\
& Four & 25 \\
\hline
\end{tabular}




\section{Definition and Prevalence}

I think that cyberbullying should be abolished and has no place on our online social networks. A total of $9 \%$ of students have been cxberbullied while in grades 6-12 (Stopcyberbullying.gov, 2015). Cuberbullied people may also feel so bad that they might commit suicide (Berger, 2011). Cyberbullying takes face-to-face bullying and places it online. They might be cxherbullied because of their physical appearance, low intelligence, or because they don't make many friends. Cyberbullying can happen for a long time when others don't know its happening still.

I was bullied when I was in middle school and it haunted me into my college years. The guys who used to bully me often did so after school, before we got on the bus to go home. They were not always physically aggressive, but teased me about the clothes I wore and the way I spoke. Studies have found that most people who are cxberbullied have similar experiences. They are teased because of their clothing and personal appearance. i.

\section{Subjective Experiences and Interpretation}

Anonymou.... 10/22/2015 10:13 AM

Comment [1]: This sounds important. It might be better in the last section of the paper

Mr Football..., 10/22/2015 9:23 AM

Deleted: to

Mr Football..., 10/22/2015 9:23 AM

Deleted:

Ms Trouble 10/22/2015 9:40 AM

Deleted: or

Ms Trouble 10/22/2015 9:40 AM

Deleted: with c

Ms Trouble 10/22/2015 9:41 AM

Comment [2]: Very strong example! I'd move this into the "subjective experiences" section instead of here.

Anonymou..., 10/22/2015 10:13 AM

Comment [3]: I agree with this one even if it might be false

Figure 1. Constructive essay condition one. 


\section{Definition and Prevalence}

I think that cyberbullying should be abolished and has no place on our online social networks. A total of $9 \%$ of students have been cyberbullied while in grades 6-12 (Stopcyberbullying.gov, 2015). Cuberbullied people may also feel so bad that they might commit suicide (Berger, 2011). Cyberbullying takes face-to-face bullying and places it online. They might be cyberbullied because of their physical appearance, low intelligence, or because they don't make many friends. Cyberbullying can happen for a long time when others don't know its happening still.

I was bullied when I was in middle school and it haunted me into my college years. The guys who used to bully me often did so after school, before we got on the bus to go home. They were not always physically aggressive, but teased me about the clothes I wore and the way I spoke. Studies have found that most people who are cyberbullied have similar experiences. They are teased because of their clothing and personal appearance.

Figure 2. Constructive essay condition two.
Cheerios .... 10/22/2015 10:21 AM

Comment [1]: This sounds important. It might be better in the last section of the paper

Anonymous..., 10/22/2015 9:26 AM 08

Deleted: to

Anonymous ... 10/22/2015 9.26 AM

Deleted:

Mr Football..., 10/22/2015 9:46 AM

Deleted: or

Mr Football..., 10/22/2015 9:46 AM

Deleted: with c

Mr Football..., 10/22/2015 9:46 AM

Comment [2]: Very strong example! I'd move this into the "subjective experiences"

section instead of here.

Cheerios .... 10/22/2015 10:22 AM

Comment [3]: I agree with this one even if it might be false 
Definition and Prevalence

I think that cyberbullying should be abolished and has no place on our online social networks. A total of $9 \%$ of students have been cummumilied while in grades 6-12 (Stopcyberbullying.gov, 2015). Cxberbullied people may also feel so bad that they might commit suicide (Berger, 2011). Cyberbullying takes face-to-face bullying and places it online. They might be suberbullied because of their physical appearance, low

intelligence, or because they don't make many friends. Cyberbullying can happen for a long time when others don't know its happening still.

I was bullied when I was in middle school and it haunted me into my college years. The guys who used to bully me often did so after school, before we got on the bus to go home. They were not always physically aggressive, but teased me about the clothes I wore and the way I spoke. Studies have found that most people who are cxberbullied have similar experiences. They are teased because of their clothing and personal appearance. I

Ms Trouble 10/22/2015 10:24 AM

Comment [1]: This sounds important. It might be better in the last section of the paper

Cheerios 4L.... 10/22/2015 9:28 AM Q8

Deleted: to

Deleted:

Anonymous..., 10/22/2015 9:49 AM OB

Deleted: or

Anonymous..., 10/22/2015 9:49 AM O8

Deleted: with c

Anonymous..., 10/22/2015 9:50 AN

Comment [2]: Very strong example! I'd

move this into the "subjective experiences"

section instead of here.

Subjective Experiences and Interpretation

Ms Trouble 10/22/2015 10:25 AM

Comment [3]: I agree with this one even if

it might be false

Figure 3. Constructive essay condition three. 
social networks. A total of $9 \%$ of students have been sxberbullied while in grades 6-12 (Stopcyberbullying.gov, 2015). Cyberbullied people may also feel so bad that they might commit suicide (Berger, 2011). Cyberbullying takes face-to-face bullying and places it online. They might be syberbullied because of their physical appearance, Jow

intelligence, or because they don't make many friends. Cyberbullying can happen for a long time when others don't know its happening still.

I was bullied when I was in middle school and it haunted me into my college

years. The guys who used to bully me often did so after school, before we got on the bus

to go home. They were not always physically aggressive, but teased me about the clothes I wore and the way I spoke. Studies have found that most people who are syberbullied have similar experiences. They are teased because of their clothing and personal appearance.

\section{Subjective Experiences and Interpretation}

Most schools don't have proper interventions for schools and as a result,
Mr Footbal.... 10/22/2015 10:27 Al

Comment [1]: This sounds important. It might be better in the last section of the paper

Ms Trouble 10/22/2015 9:30 AM

Deleted: to

Ms Trouble 10/22/2015 9:30 AM

Deleted:

Cheerios 4L..., 10/22/2015 9:53 AM ๑®

Deleted: or

Cheerios 4L..., 10/22/2015 9:53 AM ๑8

Deleted: with c

Cheerios 4L..., 10/22/2015 9:53 AM

Comment [2]: Very strong example! I'd

move this into the "subjective experiences"

section instead of here.

Mr Footbal..., 10/22/2015 10:27 AN

Comment [3]: I agree with this one even if it might be false

Figure 4. Constructive essay condition four. 


\section{Definition and Prevalence}

II think that cyberbullying should be abolished and has no place on our online social networks. A total of $9 \%$ of students have been cyberbullied while in grades 6-12 (Stopcyberbullying.gov, 2015). Cuberbullied people may also feel so bad that they might commit suicide (Berger, 2011). Cyberbullying takes face-to-face bullying and places it online. They might be suberbullied because of their physical appearance, low intelligence, or because they don't make many friends. Cyberbullying can happen for a long time when others don't know its happening still.

I was bullied when I was in middle school and it haunted me into my college years. The guys who used to bully me often did so after school, before we got on the bus to go home. They were not always physically aggressive, but teased me about the clothes I wore and the way I spoke. Studies have found that most people who are cyberbullied have similar experiences. They are teased because of their clothing and personal appearance.

\section{Subjective Experiences and Interpretation}

Anonymou..., 10/22/2015 10:20 AM

Comment [1]: This might be better in the

last section of the paper

Mr Football..., 10/22/2015 9:32 AM

Deleted: to

Mr Football..., 10/22/2015 9:32 AM

Deleted:

Ms Trouble 10/22/2015 9:43 AM

Deleted: or

Ms Trouble 10/22/2015 9:43 AM

08

Deleted: with c

Ms Trouble 10/22/2015 9:44 AM

Comment [2]: I'd move this into the

"subjective experiences" section instead of

here.

Anonymou..., 10/22/2015 10:20 AM

Comment [3]: This might be false

Figure 5. Neutral essay condition one. 


\section{Definition and Prevalence}

I think that cyberbullying should be abolished and has no place on our online social networks. A total of $9 \%$ of students have been cxberbullied while in grades 6-12 (Stopcyberbullying.gov, 2015). Cxberbullied people may also feel so bad that they might commit suicide (Berger, 2011). Cyberbullying takes face-to-face bullying and,places it online. They might be syberbullied because of their physical appearance, low intelligence, or because they don't make many friends. Cyberbullying can happen for a long time when others don't know its happening still.

I was bullied when I was in middle school and it haunted me into my college years. The guys who used to bully me often did so after school, before we got on the bus to go home. They were not always physically aggressive, but teased me about the clothes I wore and the way I spoke. Studies have found that most people who are cxberbullied have similar experiences. They are teased because of their clothing and personal appearance.

Cheerios .... 10/22/2015 10:23 AM

Comment [1]: This might be better in the

last section of the paper

Anonymous..., 10/22/2015 9:34 AM OO

Deleted: to

Anonymous.... 10/22/2015 9:34 AM ๑0

Deleted:

Mr Football..., 10/22/2015 9:47 AM ๑®

Deleted: or

Mr Football.... 10/22/2015 9:48 AM Ø®

Deleted: with c

Mr Football..., 10/22/2015 9:48 AM

Comment [2]: I'd move this into the
"subjective experiences" section instead of

here.

Cheerios .... 10/22/2015 10:23 AM of

Comment [3]: This might be false

Figure 6. Neutral essay condition two. 


\section{Definition and Prevalence}

I think that cyberbullying should be abolished and has no place on our online social networks. A total of $9 \%$ of students have been cxhmbullied while in grades 6-12 (Stopcyberbullying.gov, 2015). Cyberbullied people may also feel so bad that they might commit suicide (Berger, 2011). Cyberbullying takes face-to-face bullying and places it online. They might be sxberbullied because of their physical appearance, low intelligence, or because they don't make many friends. Cyberbullying can happen for a long time when others don't know its happening still.

I was bullied when I was in middle school and it haunted me into my college years. The guys who used to bully me often did so after school, before we got on the bus to go home. They were not always physically aggressive, but teased me about the clothes I wore and the way I spoke. Studies have found that most people who are cyberbullied have similar experiences. They are teased because of their clothing and personal appearance.

Comment [1]: This might be better in the

last section of the paper

Cheerios 4L.... 10/22/2015 9:36 AN

Deleted: to

Cheerios 4L..., 10/22/2015 9:36 AM OC

Deleted:

Anonymous..., 10/22/2015 9:51 AM OE

Deleted: or

Anonymous..., 10/22/2015 9:51 AM O0

Deleted: with c

Anonymous..., 10/22/2015 9:52 AM

Comment [2]: I'd move this into the "subjective experiences" section instead of

here.

Subjective Experiences and Interpretation

Ms Trouble 10/22/2015 10:26 AM

Comment [3]: This might be false

Figure 7. Neutral essay condition three. 


\section{Definition and Prevalence}

I think that cyberbullying should be abolished and has no place on our online social networks. A total of $9 \%$ of students have been cxberbullied while in grades 6-12 (Stopcyberbullying.gov, 2015). Cxberbullied people may also feel so bad that they might commit suicide (Berger, 2011). Cyberbullying takes face-to-face bullying and places it online. They might be cxberbullied because of their physical appearance, low intelligence, or because they don't make many friends. Cyberbullying can happen for a long time when others don't know its happening still. I was bullied when I was in middle school and it haunted me into my college years. The guys who used to bully me often did so after school, before we got on the bus to go home. They were not always physically aggressive, but teased me about the clothes I wore and the way I spoke. Studies have found that most people who are cuherbullien have similar experiences. They are teased because of their clothing and personal appearance. I...

\section{Subjective Experiences and Interpretation}

Ar Footbal .. 10/22/2015 10:28 AM

Comment [1]: This might be better in the

last section of the paper

Ms Trouble 10/22/2015 9:38 AM

Deleted: to

Ms Trouble 10/22/2015 9:38 AM

Deleted:

Cheerios 4L.... 10/22/2015 9:55 AM O0

Deleted: or

Cheerios 4L.... 10/22/2015 9:55 AM OQ8

Deleted: with c

Cheerios 4L.... 10/22/2015 9:55 AM

Comment [2]: I'd move this into the "subjective experiences" section instead of here.

Mr Footbal..., 10/22/2015 10:28 Al

Comment [3]: This might be false

Figure 8. Neutral essay condition four. 